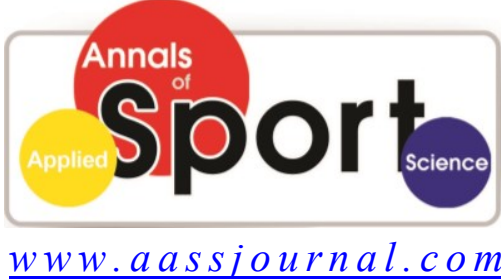

ISS N (Online): $2322-4479$
Driginal Article

Received: 06/07/2014

Accepted: 22/11/2014

\title{
The Relationship of Core Strength with Static and Dynamic Balance in Children with Autism
}

\section{${ }^{1}$ Sarvin Salar, ${ }^{*}$ Hassan Daneshmandi, ${ }^{2}$ Mohammad Karimizadeh Ardakani, ${ }^{1}$ Hossein Nazari Sharif}

1. Department of Sport Injuries and Corrective Exercises, Faculty of Physical Education and Sport Science, University of Guilan, Rasht, Iran.

2. Department of Sport Injuries and Corrective Exercises, Faculty of Physical Education and Sport Science, University of Tehran, Tehran, Iran.

\begin{abstract}
Autism represents a disorder of neural development characterized by 3 features including deficit in social communication, inflexibility of speech and behavior, and stereotyped movements. The prevalence of this disorder has been reported about 1.5 per 100 individuals in Iran. Individuals with ASDs are susceptible to weakness in balance and stability and also postural deformities. Thus, the purpose of this study was to determine the relationship between core strength and balance in children with autism. The subjects included 32 boys with ASDs aged 6-10 (mean and standard deviation of $8.16 \pm 1.16$ years, $124.81 \pm 11.56 \mathrm{~cm}$ in height, $33.02 \pm 7.72 \mathrm{~kg}$ weight and body mass index $21.12 \pm 3.14 \mathrm{~kg} / \mathrm{m}^{2}$ ). They were selected according to available sampling method. In order to assess the maximum isometric strength of hip abduction and external rotation, manual muscle test dynamometer was used. Static and dynamic balance were also tested by modified stork standing test and walking heel to toe test, respectively. The results showed that there is no correlation between core strength and static balance in dominant and non-dominant leg, but there is a significant correlation between dynamic balance and core strength. According to the results, it is recommended that development of parameters related to the core body strength to be emphasized for improving balance in such children.
\end{abstract}

Key Words: Autism, Core Strength, Balance, Hip Abduction, Hip External Rotation.

Corresponding Author:

Sarvin Salar

E-mail: sarvin_salar@yahoo.com 


\section{INTRODUCTION}

Autism spectrum disorder (ASD) is a lifelong neuropsychiatric disorder which falls into the category of pervasive developmental disabilities. This disorder, which is often mistakenly thought to be identical with mental retardation, was firstly described by Leo Conner in 1943. These disorders include autism, Asperger, and pervasive developmental disabilities not otherwise specified (PDD-NOS), the first two ones are of the main forms of autism spectrum disorders (1). 75 to 80 percent of children with pervasive developmental disorders are boys, while the severity of autism and possibility of mental retardation are higher in girls. The majority of such individuals are mentally retarded and about $20 \%$ of them have a normal intelligence $(2,3)$. Initial studies have estimated the prevalence of ASD to be less than 10 persons per 10 thousand people. However, current studies have demonstrated a significant increase in the prevalence of ASD (110 persons per 10 thousand people) (4). Ghanizadeh (2008) reported that the prevalence of ASD in Iran is equal to 250 persons in 10000 people (5).

Although autism is considered as a mental disorder, it is often associated with physical and systematic disorders. These disorders include sensory differences, sensorimotor disorders, motor growth, walking, joints mobility, motor skills, physical fitness, balance, muscle weakness, and hypotonia (6). Children and adolescents with ASD suffer from poor coordination of the upper limbs during the performance off visual-motor tasks and hand dexterity and poor coordination of lower limbs during activities requiring balance, agility, and speed (7). In addition, autistic children have low levels of physical fitness which prevents them from participating in recreational and social activities and causes them to lead inactive and sedentary life (8). The results of a study also showed that there is a significant difference between children with ASDs and healthy ones in terms of all physical fitness parameters such as 600-yard running, sit-up, muscle strength and endurance, static and dynamic balance, flexibility, kyphosis, lumber scoliosis, and genu valgus (9). Weakness of autistic children in basic motor skills, mobility skills, objects control, and gross and fine motor skills has been mentioned in many studies $(7,8)$. Ming, Brimacombe, and Wagner (2007) studied the prevalence of motor impairment in individuals with autism and fond that motor impairment is common in children afflicted with ASDs (1). Also, it has been reported that motor impairment occurs in $50 \%$ of children with Asperger and 65\%of them with autism (3). Molloy, Dietrich, and Bhattacharya (2003) studied postural stability in children with ASDs and concluded that this groups of children show higher fluctuations in all states of test compared with healthy children (10). Engel (2011) showed that autistic children often show an apparent unusual posture and center of gravity (11). Although few studies have been conducted on muscular strength of autistic individuals, it has been reported that some children with autism have less muscle strength than their healthy peers. Kern et al. (2011) stated that children suffering from ASDs have a poor muscle strength, which is related to the severity of their disorder (6).

Core stability is the capability of lumbarpelvic-hip complex to avoid instability of the spine and return to equilibrium after a perturbation (12). The core of body can be assumed as a box in which abdominal muscles, paraspinal and gluteal muscles, diaphragm muscle, and thigh muscles are located in the front, back, top, and floor (13). It has been shown that the muscles in the core of body are activated before the extremities perform a motion (14). These muscles serve as a bridge between the upper and lower limbs and this way power is produced in the core of body and transferred to organs. 
Primarily, stability requires maintaining the neutral state of backbone but it should also exists in the case that backbone is out of the neutral state (12).

According to the results of previous research and review studies, a set of core strength, core endurance, and lumbar-pelvic muscle control structure forms core stability. Therefore, it is necessary to describe different aspects of core stability components $(12,15)$. Strength is the maximum force that a muscle or a group of muscles can produce at a specific rate. Hence, core strength is attributed to the ability of muscle contraction of core muscle structure and stabilizing the backbone. Core strength in controlling the stability of backbone through regulation of surrounding muscles force. Thus, core strength is essential for core stability (16). Studies have shown that reduced strength in the muscles of the core of body increases body fluctuations and may disrupt the body balance (17). According to the theory of closed kinetic chain, thigh muscles strength is effective in performance of lower extremities, controlling the lower segments, and prevention of injuries and if one of the joints of lower extremities has a poor performance, other joints will be involved. The results of a study showed that athletes with stronger abductor and rotator muscles did not face lower extremities injuries at the of a sports season $(14,17)$.

In addition, the importance of balance control can be discusses in three field of motor and sports skills, injuries, and rehabilitation. Biomechanically, balance is the ability to maintain the body's center of gravity in the range of base of support with the minimum fluctuation and the maximum stability. Factors affecting the maintenance of balance involve sensory information that is obtained from somatic sensory, vestibular, and visual systems and is influenced by coordination, joint range of motion, and muscular strength (10).
Studies have generally shown the role of core stability in improving athletic performance and preventing the injuries. Some researchers have studied the relationship of balance with strength and endurance of core muscles for promoting athletic performance, finding the talents, preventing the falling and injuries among the elderly, improving the processes of rehabilitation, and reducing the treatment costs of injuries caused by loss of balance (18, 19). Hence, given the importance of balance and core stability (and its components) as a key factor in maintaining the posture and as the majority of studies in this regard have been conducted on healthy individuals, athletes, and individuals with back pain and paucity of such studies on individuals with special disabilities, the present paper aims to study the relationship between the strength of core muscles and balance in order to identify the factors affecting impaired balance and postural stability in autistic children.

\section{MATERIALS AND METHODS}

Participants. Statistical population included all boys with autism spectrum disorder in Tehran in 2014, 32 of them were selected as the sample by accessible sampling method. Mean and standard deviation of subjects' age, height, weight, and Body Mass Index (BMI) were equal to $8.16 \pm 1.16$ years, $124.81 \pm 11.56 \mathrm{~cm}, 33.02 \pm 7.72 \mathrm{~kg}$, and $21.12 \pm 3.14 \mathrm{~kg} / \mathrm{m}^{2}$, respectively. After filling out the parental consent form, information such as classification based on GARZ scale and cardiovascular, pulmonary, and musculoskeletal conditions of subjects were obtained from their medical records. No visual impairment and lack of orthopedic, cardiovascular, vestibular system, and somatic sensory system problems were the entry criteria. In addition, eye screening was done and those with obvious abnormalities were excluded from the study.

Data Collection. The tests were performed in the morning at the Behara Training and 
Rehabilitation Center for Autistic Children. In order to determine the dominant foot, the subjects were asked to shoot a ball. Maximum isometric hip abduction strength and maximum isometric hip external rotation strength tests were used for evaluation of core muscles strength (19). Static and dynamic balance were also measured by modified stork standing test and walking heel to toe test, respectively $(8,9)$. Before the test, while the subject was getting ready, he was asked to do three submaximal isometric contractions as a warm-up and for getting familiar with the test. Instead of simulation of manual resistance by the examiner, stabilizer straps were used in these tests for creating resistance in the desired site. These modifications to the resistance simulation method minimize the errors caused by variability in the examiner's hand strength and improve the clinical advantages of manual dynamometers (14).

Maximum Isometric Hip External Rotation Strength Test. To perform this test, subjects were asked to sit down on the edge of a bed as their thighs are flexed to an angle of 90 degrees. To prevent the activity of hip adductors, a small cushion was put between the thighs and the subjects were asked to put their hands stretched on the edge of the bed. The center of handheld dynamometer pad force at a distance of $5 \mathrm{~cm}$ to the medial malleolus proximal was fixed by a strap (Figure 1). In addition, another strap was fastened around the foot of subjects and the bed base in order to fix the body position. Subjects were asked to perform the hip external rotation motion and hold the contraction for 5 seconds. This test was repeated 3 times with 15 seconds rest between each attempt. The mean of three attempts scores were recorded as the score of subjects on this test. Maximum isometric hip external rotation strength test was done for both dominant hand and non-dominant hand (19).

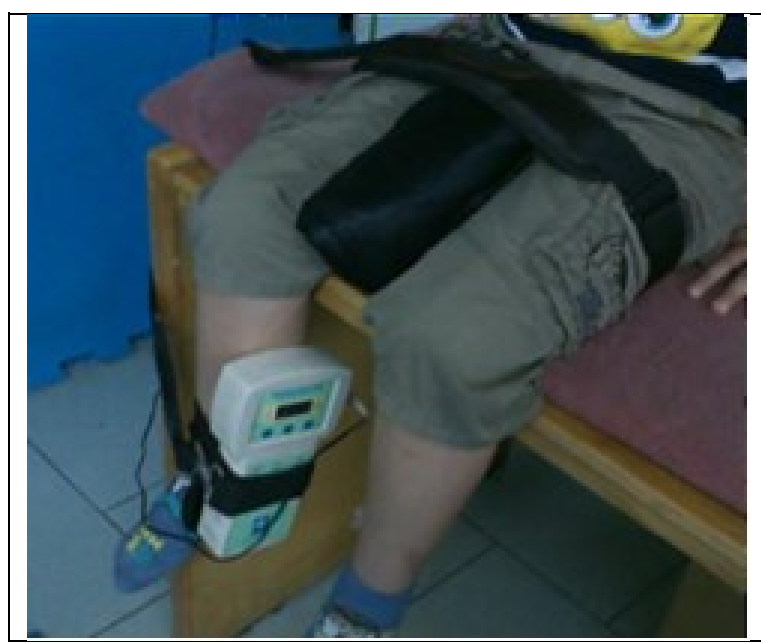

Figure 1. Maximum isometric hip external rotation strength test.

Maximum Isometric Hip Abduction Strength Test. For this test, the subjects were asked to laterally lie down on examination bed and a small cushion was put between their hips, so that the upper hip is in a normal 10-degree abduction position. A strap fastened on top of iliac crest and the bed was used for fixing the body position. The center of handheld dynamometer pad force was fixed directly on the determined sign at a distance of 5 $\mathrm{cm}$ to the proximal of knee joint lateral line (Figure 2). Another strap was also fastened around the dynamometer and the bed. While relying on the forearm of one hand and putting the other hand on the chest, the subject was asked to do the motion of moving the hip upward with maximum effort and hold the contraction for 5 seconds. This test was repeated 3 times with 15 seconds rest between each attempt. Maximum hip abduction strength in 3 successive isometric contraction was recorded as the final score of subjects. Maximum isometric hip abduction strength test was done for both dominant hand and non-dominant hand (19). 


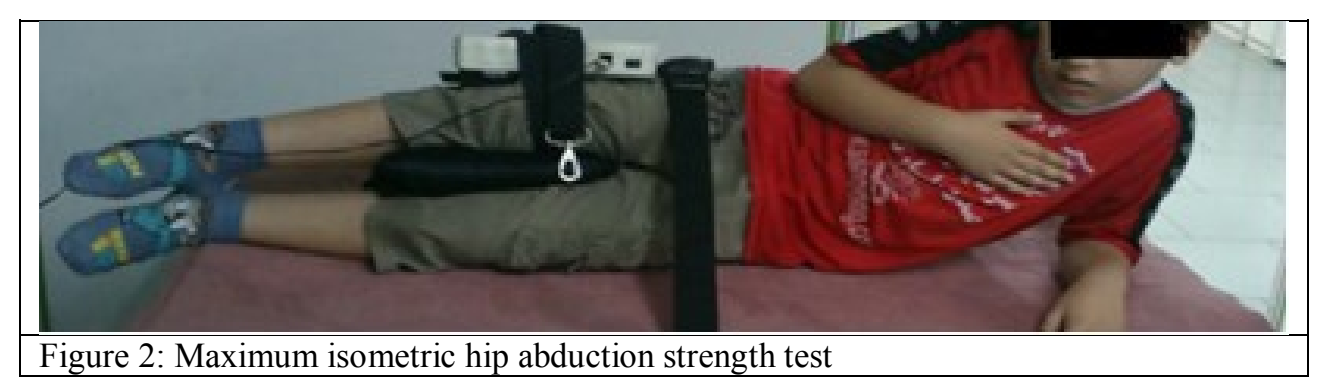

After the core strength tests, the length of the lever arm of hip and knee joints in dominant foot was measured. The proximal sign of lever arm in hip and knee joints was, respectively, in line with the greater trochanter and the center of the knee joint and its distal end was considered as the place where the center of dynamometer head is put. Then, the torque was calculated for each muscle group and normalized based on height and weight of the subjects (20).

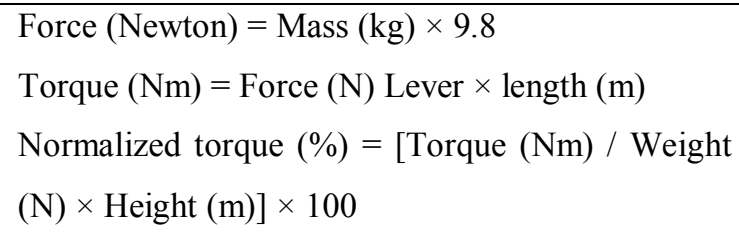

Measurement of Static Balance. Modified stork standing test was used for evaluation of static balance. In this test, the subjects were asked to stay one flat surface with one leg (the fulcrum leg), raise the free leg to the ankle of the fulcrum leg, and put their hands besides the body. When the free leg was back to the floor, the time was stopped and recorded.
This test was done 2 times for each leg and the maximum time was considered as the record of each subject $(8,9)$.

Measurement of Dynamic Balance. To assess the dynamic balance, walking heel to toe test was applied. In this test, the ability of subjects to walk in a straight line from heel to toe is measured. The subjects were asked to walk in a specified path with a length of 15 steps from heel to toe. If the subjects stray from the path before completing the 15 steps, the test is stopped and the number of steps is recorded as their score. This test was performed two times and the best score was considered as the record of subjects $(8,9)$.

Statistical Analysis. SPSS 19 software was used for data analysis. Normality distribution of variables was examined by Kolmogorov-Smirnov test. Since the distribution of data was normal $(p<0.05)$, Pearson correlation test was used for studying the relationship between all factors and variables of the present paper.

\section{RESULTS}

Table 1 present the descriptive information.

Table 1. Mean and standard deviation of the measured variables

\begin{tabular}{lccc}
\hline & Test type & Mean & SD \\
\hline Total hip abductor strength & & 3.58 & 1.45 \\
Total hip external rotation & 4.55 & 2.05 \\
Total abduction strength and external rotation (Core strength) & 8.09 & 3.37 \\
Static balance (second) & 9.40 & 5.26 \\
Dynamic balance (step) & 7.93 & 3.77 \\
\hline
\end{tabular}


According to the results of the Pearson correlation test, there is a significant $(\mathrm{P}<0.01)$ relationship between dominant and non-dominant leg abduction strength, dominant and non-dominant leg external rotation, and core strength and dynamic balance. By contrast, there is no relationship between the components of core strength and static balance and only a significant relationship can be observed between hip abduction strength and static balance (Table 2).

Table 2. The results of Pearson correlation test

\begin{tabular}{|c|c|c|c|c|c|c|c|}
\hline & $\begin{array}{l}\text { Dominant } \\
\text { hip } \\
\text { abduction } \\
\text { strength }\end{array}$ & $\begin{array}{l}\text { Non- } \\
\text { dominant } \\
\text { hip } \\
\text { abduction } \\
\text { strength }\end{array}$ & $\begin{array}{l}\text { Total hip } \\
\text { abduction } \\
\text { strength }\end{array}$ & $\begin{array}{l}\text { Dominant } \\
\text { hip external } \\
\text { rotation } \\
\text { strength }\end{array}$ & $\begin{array}{c}\text { Non- } \\
\text { dominant } \\
\text { hip external } \\
\text { rotation } \\
\text { strength }\end{array}$ & $\begin{array}{l}\text { Total hip } \\
\text { external } \\
\text { rotation } \\
\text { strength }\end{array}$ & $\begin{array}{l}\text { Total core } \\
\text { strength }\end{array}$ \\
\hline $\begin{array}{c}\text { Dominant } \\
\text { leg static } \\
\text { balance }\end{array}$ & $\begin{array}{l}r=0.285 \\
p=0.114\end{array}$ & $\begin{array}{l}r=0.333 \\
p=0.063\end{array}$ & $\begin{array}{l}\mathrm{r}=0.311 \\
\mathrm{p}=0.083\end{array}$ & $\begin{array}{l}r=0.161 \\
p=0.373\end{array}$ & $\begin{array}{l}r=0.277 \\
p=0.125\end{array}$ & $\begin{array}{l}\mathrm{r}=0.223 \\
\mathrm{p}=0.221\end{array}$ & $\begin{array}{c}r=0.336 \\
p=0.6\end{array}$ \\
\hline $\begin{array}{c}\text { Non- } \\
\text { dominant } \\
\text { static } \\
\text { balance } \\
\end{array}$ & $\begin{array}{c}\mathrm{r}=0.401 \\
\mathrm{p}=0.023^{*}\end{array}$ & $\begin{array}{c}r=0.419 \\
p=0.017 *\end{array}$ & $\begin{array}{c}r=0.427 \\
\mathrm{p}=0.015^{*}\end{array}$ & $\begin{array}{l}r=0.208 \\
p=0.254\end{array}$ & $\begin{array}{l}r=0.287 \\
p=0.124\end{array}$ & $\begin{array}{l}r=0.248 \\
p=0.171\end{array}$ & $\begin{array}{c}r=0.328 \\
p=0.67\end{array}$ \\
\hline $\begin{array}{l}\text { Dynamic } \\
\text { balance }\end{array}$ & $\begin{array}{c}\mathrm{r}=0.471 \\
\mathrm{p}=0.042 *\end{array}$ & $\begin{array}{c}\mathrm{r}=0.541 \\
\mathrm{p}=0.007 * *\end{array}$ & $\begin{array}{c}r=0.512 \\
p=0.001 * *\end{array}$ & $\begin{array}{c}r=0.545 \\
p=0.001 * *\end{array}$ & $\begin{array}{c}r=0.556 \\
p=0.001 * *\end{array}$ & $\begin{array}{c}\mathrm{r}=0.566 \\
\mathrm{p}=0.001 * *\end{array}$ & $\begin{array}{c}\mathrm{r}=0.564 \\
\mathrm{p}=0.001 * *\end{array}$ \\
\hline
\end{tabular}

$*$ : Significant level at $\mathrm{p}<0.05$. **: Significant level at $\mathrm{p}<0.01$.

\section{DISCUSSION AND CONCLUSION}

According to the results of the present study, there is a significant relationship between all components of core strength and dynamic balance, while there is no relationship between core strength and static balance in dominant and non-dominant leg and only a significant relationship was found between non-dominant leg static balance and dominant hip abduction strength. In addition, no significant relationship was observed between non-dominant and dominant hip external rotators strength and static balance.

In recent years, there has been much emphasis on developing the strength and endurance of trunk or core body, because it is the origin of body movements and an essential component of the kinetic chain. For sports and many other functional tasks, the core body is a key chain in the beginning-toend sequence in the transmission path from the ground to the upper limbs. Inefficiency in the central part of the body may affect individual performance and facilitate the occurrence of injuries (21). Both athletes and sedentary individuals are at the risk of hip joint damages. Slight weakness of the hip can cause changes in the biomechanics of the lower extremity and cause pain in the legs and knees. For example, a person who is suffering weakness in hip muscle strength show overbending of back when performing the motion Scott. If the incorrect movement patterns are repeated over time, such people will be at risk of injury (22).

In a research conducted by Bazgirinejad, Noraste, and Banparvari (2013), Star Excursion Balance Test was used for measuring the dynamic balance and core muscle strength was measured by step down, hip abductor strength isometric, and hip external rotation strength tests. They found a significant positive relationship of core muscle strength, dominant leg external rotators strength, non-dominant leg external rotators strength, dominant leg abductors 
strength, and step down with dynamic balance (23). This is consistent with the findings of the present study. Naseri et al. (2012) performed two sets of tests for core stability (isometric hip abduction and external rotation test, moving downward two lower limbs simultaneously, extensionflexion endurance and lateral flexion tests) and lower extremity function (Star Excursion Balance Test in three directions, vertical jump, one single-foot leaps, three single-foot leaps, leap running at the staircase, 6-meter single-foot leap, and reciprocating running) on 40 female athletes. Their results showed that hip abductors isometric strength has a significant direct relationship with star excursion balance in the direction of extension. They also found that most tests of core stability have a weak or moderate and even inverse relationship with lower extremity function tests (24). Ghotbi, Khodabakhshi, and Jalaei (2012) applied Berg's Scale and the Motricity Index in order to assess balance and muscle strength of organs in 63 patients with MS. For evaluation of strength, hip flexion, knee extension, and ankle dorsiflexion motions were tested. The results showed that there is a significant relationship between balance and muscle strength of lower and upper limbs in patients with impaired balance, but such a relationship was not observed in patients without impaired balance (25). Ringsberg et al. (1999) studied the relationship between muscle strength and balance in elderly women. They evaluated balance by force plate and clinical test of standing on one leg. Maximal isometric knee extension and flexion and ankle dorsiflexion were also measured by Biodex dynamometer. The results showed that there is no relationship between the simple balance test of standing on one leg and balance tests (26), which is in consistent with the findings of the present study. Thorpe and Ebersole (2008) studied the relationship of SEBT and lower extremity muscle strength and concluded that lower extremity muscle strength has no relationship with SEBT (27). This is inconsistent with the results of the present study. This discrepancy can be attributed to the type of tests used and characteristics of subjects in terms of age, physical fitness, and physiological and psychological issues.

In regard to the core strength, Saunders (2007) reported that exercises of abductor muscles and hip external rotators are often desirable in the core stability programs for improving the control of lumber-pelvic motion in the frontal plane. This is of importance in slow walking to running, as reduced hip strength leads to poor control of lumber-pelvic posture and thereby insufficiency of the lower extremity. In addition, as muscular structural of hip is very important in communicating with the lower extremities and transmission of force from/to the center, it should be taken into account and discussed when speaking about the core stability (28).

In the present study, muscle strength of abductors and hip external rotators were measured. According to what has been extracted from previous studies and the theory of closed kinetic chain, hip muscle strength is essential for controlling the lower segments of the body and increased hip abductors strength causes increased ability of controlling the direction of the lower limbs and reduced load on the lower limb joint during increasing body movement in sports activities $(15,29)$.

Therefore, it can be generally stated that the core stability is a platform for effective biomechanical function of extremities which increases force generation and reduces joint loads in all activities from running to throwing. It is not exactly known that the core part is consisted of what anatomical and physiological components $(15,30)$, that's why physical assessment of the core stability seems to be complicated and different. Kibler, Press, and Sciascia (2006) stated that assessment of the core stability should be dynamic and such an assessment can involve 
special functions such as postural control and its movements in three motor plats during an activity (30). In the present and similar studies, isometric tests have been used for evaluation of the core stability. Isometric tests assess the muscles only at a certain length and so cannot represent the actual performance of muscles. However, due to the complexity of mechanisms involved in creating the core stability, it seems that the actual capacity of the core body cannot be estimated based on the results of such test $(14,30)$.

The results of the present study suggest a significant relationship between dynamic balance and the core strength, while such a relationship was not found between static balance and the core strength. This insignificance can be attributed to particular circumstances of the subjects, different measurement tools, weakness of subjects in static balance, and low strength of their lower limbs. The type of tests used for measuring the balance can be mentioned as another reason for conflict between the results of the present study and other ones. In many studies, Biodex isokinetic device or other functional tests are used (29). Age, gender, and number of subjects, specific characteristics of the subjects in terms of physical and postural weaknesses, their poor physical fitness, neuropsychological problems, and different responses of the central nervous system in autistic individuals (8) are some other constraints of the present research. According to the paucity of studies on the core stability and strength in children with autism, it is recommended that further studies to be conducted on girls with more number of subjects, more advanced tools, and also in comparison with other groups of individuals with disabilities.

In addition, according to the findings of the present study, it is recommended that core strength components such as dominant leg external rotators strength, non-dominant leg external rotators strength, dominant leg abductors strength, and non-dominant leg abductors strength to be seriously taken into account in order to improve balance. We hope that the results of the present study would be a helpful and effective guide for coaches and sports professionals, therapists, and physiotherapists who are somehow in contact with this group of children.

\section{REFFRENCES}

1. Ming X, Brimacombe M, Wagner GC. Prevalence of motor impairment in autism spectrum disorders. Brain \& development. 2007;29(9):565-70.

2. Baio J. Prevalence of Autism Spectrum Disorders: Autism and Developmental Disabilities Monitoring Network, 14 Sites, United States, 2008. Surveillance Summaries. 2012;61(3):1-19.

3. Papadopoulos N, McGinley J, Tonge B, Bradshaw J, Saunders K, Murphy A, et al. Motor proficiency and emotional/behavioural disturbance in autism and Asperger's disorder: another piece of the neurological puzzle? Autism : the international journal of research and practice. 2012;16(6):627-40.

4. Matson JL, Kozlowski AM. The increasing prevalence of autism spectrum disorders. Research in Autism Spectrum Disorders. 2011;5(1):418-25.

5. Ghanizadeh A. A preliminary study on screening prevalence of pervasive developmental disorder in schoolchildren in Iran. Journal of autism and developmental disorders. 2008;38(4):759-63.

6. Kern JK, Geier DA, Adams JB, Troutman MR, Davis G, King PG, et al. Autism severity and muscle strength: A correlation analysis. Research in Autism Spectrum Disorders. 2011;5(3):1011-5.

7. Bhat AN, Landa RJ, Galloway JC. Current perspectives on motor functioning in infants, children, and adults with autism spectrum disorders. Physical therapy. 2011;91(7):1116-29.

8. Pan CY. Motor proficiency and physical fitness in adolescent males with and without autism spectrum disorders. Autism : the international journal of research and practice. 2014;18(2):156-65.

9. Forti S, Valli A, Perego P, Nobile M, Crippa A, Molteni M. Motor planning and control in autism. A kinematic analysis of preschool children. Research in Autism Spectrum Disorders. 2011;5(2):834-42.

10. Molloy CA, Dietrich KN, Bhattacharya A. Postural stability in children with autism spectrum disorder. Journal of autism and developmental disorders. 2003;33(6):643-52. 
11. Engel A. Physical Activity Participation in Children with Autism Spectrum Disorders: An Exploratory Study. Canada: University of Toronto; 2011.

12. Willson JD, Dougherty CP, Ireland ML, Davis IM. Core stability and its relationship to lower extremity function and injury. The Journal of the American Academy of Orthopaedic Surgeons. 2005;13(5):316-25.

13. Hodges PW, Richardson CA. Contraction of the abdominal muscles associated with movement of the lower limb. Physical therapy. 1997;77(2):132-42; discussion 42-4.

14. Leetun DT, Ireland ML, Willson JD, Ballantyne BT, Davis IM. Core stability measures as risk factors for lower extremity injury in athletes. Med Sci Sports Exerc. 2004;36(6):926-34.

15. Akuthota V, Ferreiro A, Moore T, Fredericson M. Core stability exercise principles. Current sports medicine reports. 2008;7(1):39-44.

16. Granacher U, Gollhofer A. Is there an association between variables of postural control and strength in adolescents? Journal of strength and conditioning research / National Strength \& Conditioning Association. 2011;25(6):171825.

17. Bouisset S. [Relationship between postural support and intentional movement: biomechanical approach]. Archives internationales de physiologie, de biochimie et de biophysique. 1991;99(5):A77-92.

18. Hodges PW. Core stability exercise in chronic low back pain. The Orthopedic clinics of North America. 2003;34(2):245-54.

19. McCaskey A. The Effects of Core Stability Training on Star Excursion Balance Test and Global Core Muscular Endurance: University of Toledo; 2011.

20. Krause DA, Schlagel SJ, Stember BM, Zoetewey JE, Hollman JH. Influence of lever arm and stabilization on measures of hip abduction and adduction torque obtained by hand-held dynamometry. Archives of physical medicine and rehabilitation. 2007;88(1):37-42.

21. Petrofsky JS, Cuneo M, Dial R, Pawley AK, Hill J. Core strengthening and balance in the geriatric population. The Journal of Applied Research. 2005;5(3):423-33.

22. Petrofsky JS, Batt J, Davis N, Lohman E, Laymon M, De Leon GE, et al. Core muscle activity during exercise on a mini stability ball compared with abdominal crunches on the floor and on a swiss ball. The Journal of Applied Research. 2007;7(3):255-72.

23. Bazgirinejad F, Noraste AA, Banparvari M. Relationship between core strength and dynamic balance in Alpine skiers. Journal of Biological Science and Physical Activity. 2013;1(2):46-57 [Article in Farsi].

24. Naseri N, Fakhari Z, Senobari M, Sadria G. The relationship between core stability and lower extremity function in female athletes. Modern Rehabilitation. 2012;6(2):42-9 [Article in Farsi].

25. Ghotbi N, Khodabakhshi Z, Jalaei S. The relationship between balance disorder, muscular strength and disability rate in Iranian patients with multiple sclerosis. Modern Rehabilitation. 2012;6(1):44-8 [Article in Farsi].

26. Ringsberg K, Gerdhem P, Johansson J, Obrant KJ. Is there a relationship between balance, gait performance and muscular strength in 75-year-old women? Age and ageing. 1999;28(3):289-93.

27. Thorpe JL, Ebersole KT. Unilateral balance performance in female collegiate soccer athletes. Journal of strength and conditioning research / National Strength \& Conditioning Association. 2008;22(5):1429-33.

28. Saunders S. Core stability and exercise prescription: a research update: implications for physiotherapists. Sport Health. 2007;25(1).

29. Fabunmi AA, Gbiri CA. Relationship between balance performance in the elderly and some anthropometric variables. African journal of medicine and medical sciences. 2008;37(4):321-6.

30. Kibler WB, Press J, Sciascia A. The role of core stability in athletic function. Sports medicine (Auckland, NZ). 2006;36(3):189-98. 
تازههاى علوم كاربردى ورزش

دوره دوم، شماره جهارم

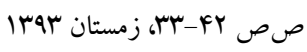

مقاله اصيل

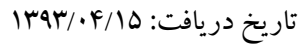

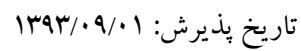

\section{ارتباط قدرت مركزى با تعادل ايستا و يويا در كودكان اتيسم}

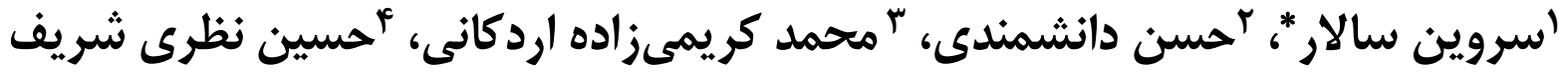

ا. دانشجوى كارشناسى ارشد آسيب شناسى ورزشى و حركات اصلاحى، دانشكده تربيت بدنى و علوم ورزشى، دانشخاه گيلان، رشت، ايران.

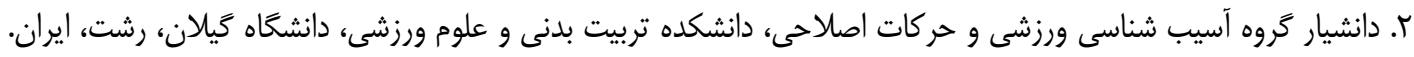

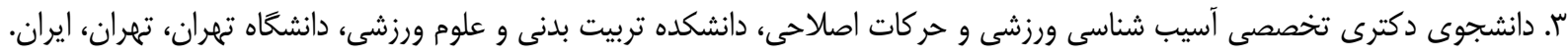

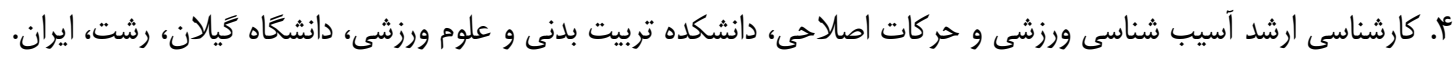

جكيده

اختلال اتيسم بيانكَ نوعى اختلال رشد عصبى با سه ويزّى مشخص نقص در ارتباطات اجتماعى، انعطافيذير نبودن كفتار و رفتار، و حركات

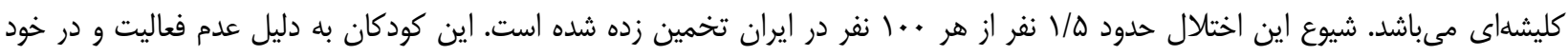

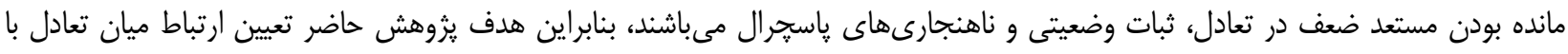

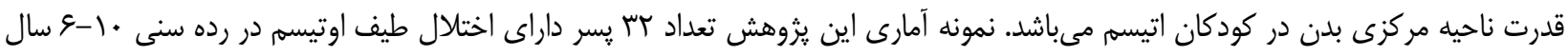

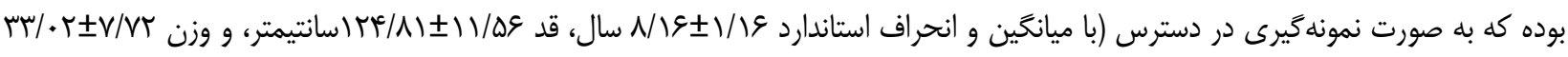

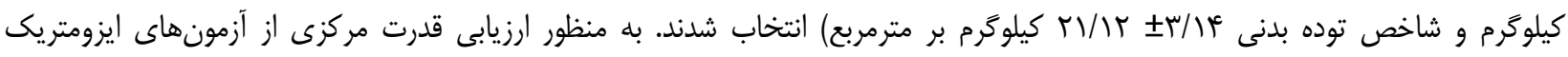

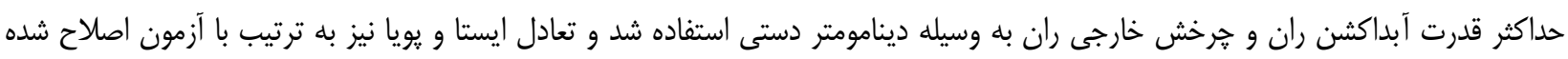

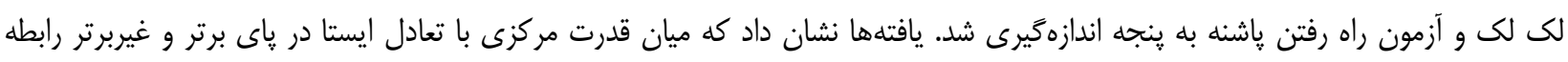

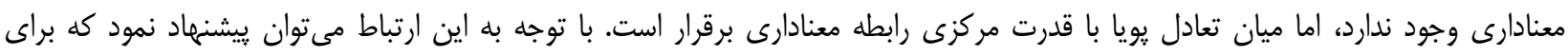

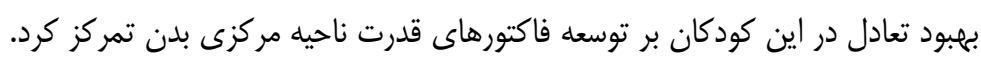
وازَٔان كليدى: اختلال اتيسه، قدرت مركزى، تعادل، ابداكشن ران، خرخش خارجى ران. 